\title{
Analysis of Investment Risks as a Complex System Using Fuzzy Logic and Uncertainty Management Methods
}

$$
\text { Garnov }^{1} \text {, L. Zvyagin }{ }^{2} \text {, O. Sviridova }{ }^{3}
$$

\begin{abstract}
:
Purpose: In order to effectively handle complex projects, managers need to adopt a pluralistic approach to practice. They should be able to use a wide range of tools and ways of thinking to develop their own methods, their own practice models, freely, according to the needs of a project. The article is aimed at presenting the comprehensive approach in evaluating and analyzing investment risks.

Design/Methodology/Approach: When studying the use of fuzzy logic methods, it is necessary to determine the main drawbacks and limitations of the current economic and mathematical models, as well as methods for evaluating the effectiveness and risks of projects.

Findings: Using fuzzy logic, authors analyzed risk categories in two key stages by examining the net present value index. Authors applied the method of risk assessment based on the integrated risk assessment $V \& M$, forming full range of investment scenarios and determining the unacceptable risk values.

Practical Implications: The authors' approach could be applied in predicting changes in economic activity under the influence of external and internal factors.

Originality/Value: The study highlights the key features of fuzzy logic methods in analyzing projects when processes are difficult to formalize, and subjective criteria exist.
\end{abstract}

Keywords: Analysis, investment risks, complex systems, fuzzy logic methods.

JEL Code: C23, C65.

Paper Type: Research article in Special Issue dedicated to Russian Economy.

Section 8: Business and Economic Issues.

\footnotetext{
${ }^{1}$ Plekhanov Russian University of Economics, Moscow, profgarnov@yandex.ru

${ }^{2}$ Financial University under the Government of the Russian Federation, Moscow, saineco@yandex.ru

${ }^{3}$ Financial University under the Government of the Russian Federation, Moscow, olshan@list.ru
} 


\section{Introduction}

In recent years, the need for complex systems to respond to different needs in an increasingly interconnected and interdependent environment has increased. For example, the air traffic control system operations on the stock exchange or the risk management system. The increasing complexity of such systems leads to complication of the management of projects, which requires a revision of the generally accepted methodologies to provide a more effective response to the expectations of the success of the planned projects. In the presence of analytical measurement of time, cost and quality, each participant of the project has its own view on the implementation of the project. The inevitable differences in the views of the various stakeholders were formalized in a functional gap, which can be interpreted as an inverse measure of the degree of harmony between the two actors in relation to the measurement of the analysis under consideration.

The scale and the complexity of projects carried out by public or private organizations have increased significantly. This can be explained by the increasing complexity of the products being developed and the constraints on development time. Projects are increasingly managed at a very rapid pace, which adds to the difficulties and reduces the possibility of achieving goals such as timely implementation, budget expenditures and expected quality. Statistical estimates show that projects fail at an alarming rate. The common reasons are the vague goals and specifications of the project, as well as inadequate solutions resulting from poor design or incorrect implementation, but also the lack of participation of various stakeholders in the project, especially when their views are not consistent. The traditional approach to project management assumes that the context of the project remains the same, and the key factors for the success of the project are explained by unambiguous elements of management and control. Many project plans are based on a static view of the world defined at the time the project starts; as a result, the plan remains valid until what has been planned as a model for the future is retained. In fact, the project environment rarely remains static, and planning assumptions change over time.

\section{Literature Review}

A review of the literature indicates that the common factors among projects for the recognition of the complexity of the object and projects are the complex characteristics, technical compliance, cost overruns, conflicts of schedules and political problems. There are several reasons why the technical content of programs can become complex, such as the development of technological and new software, the interaction with several complementary projects and programs, the development of important systems and several integrated interfaces and users. This item also applies to technologies that are not fully developed and which require more work and development after the completion of design and construction. 
Finance is also a complex task. This varies from project funding, which is insufficient to achieve the desired requirements and how the input money is planned to be used in the project. This is often influenced by politicians who, for various reasons, have different views on projects and their ratings. Complex negotiation processes within development projects can mitigate unforeseen financial losses during the testing and development phases. Each of these elements is a source of boundless variables, the variability of which is generally considered to be the cause of many project problems. Project plans should be detailed and comprehensive, using an optimal mix of skills. Developing these plans to properly mitigate risks is essential to maximize opportunities without compromising project safety. Project management flexibility is described as the ability of project managers to respond quickly to a threat or opportunity and is encouraged by the evaluation of project effectiveness, especially in the context of risk, uncertainty and decision-making.

The question of determining the complexity of projects is currently under discussion. This is because the complexity of the project is not easy to define and relies on the unique circumstances of the scenario to justify its characterization. For example, linguistic dictionaries define the word "complex" as "consisting of parts" and "complex, showing difficulties for analysis or unraveling". This is what is meant when complex adaptive systems are pragmatically described as consisting of many components interacting with each other in a complex way, where its size is larger than the total sum of smaller objects.

The theory of fuzzy sets offers several methods that relate to the methods of evaluation and decision-making when making the fact of uncertainty in the object of activity. Their main task is to give the initial data a formalized form, as well as their main function is to achieve the greatest efficiency of the project using a fuzzy interval, i.e., vector interval values. It should be noted that a certain degree of uncertainty is always present when entering any interval. With the help of certain operations, for example, arithmetic, with these fuzzy intervals, according to all the rules and laws of fuzzy logic, the final (resulting) interval for the final (target) indicator is obtained. As for the boundaries of the interval, they are calculated mainly by expert means based on initial information, experience and other factors of the expert. When studying the use of fuzzy logic methods, it is necessary to determine the main drawbacks and limitations of the current economic and mathematical models, as well as methods for evaluating the effectiveness and risks of projects in comparison with the methods of fuzzy numbers. Now, the following disadvantages are highlighted:

$\checkmark$ A sufficiently high proportion of the risk of incorrect subjective assessment when assigning probabilities of expert assessments;

$\checkmark$ Often the main problem is the lack of statistical information for the reasonable application of probabilistic methods;

$\checkmark$ The relatively low level of classification uncertainties. 


\section{Results}

The main characteristic of fuzzy set theory is the manipulation of a component as a linguistic variable. A linguistic variable is a variable whose values are not numbers, and words and expressions that cause blurring because they do not have a specific numeric value. Each linguistic variable consists of: header's; the set of its values, which is also called the base term; universal sets; syntactic rules of $G$ that are created in the new environment by using the words natural or formal language; semantic rules $P$, which assigns a fuzzy subset $X$ to each value of a linguistic variable.

Linguistic variables are the building blocks of a fuzzy set system. The probability of risk can be considered as a numerical value in the range of intervals $[0,100 \%]$, so is a linguistic variable that can take values such as high, moderate, low, etc. Each of these linguistic values can be interpreted as a label of a fuzzy subset of discourse $\mathrm{X}$ $=[0,100 \%]$, a basic variable which $(\mathrm{x})$ is a general numerical capacity risk. The fuzzy set is defined as a class of objects with a continuum of degrees of membership. It further characterizes the fuzzy set (class) a in X on the membership of the function $(\mathrm{MF}), \mu_{\mathrm{A}}(x)$, which associates with each point $\mathrm{x}$ a real number in the interval $[0,1]$, with the value $\mu_{\mathrm{A}}(x)$, on $\mathrm{X}$, which is the "degree of membership" of $\mathrm{X}$ to $\mathrm{A}$. It follows that the fuzzy set is defined as a match: $\mu: X \rightarrow[0,1]$. Figure 1 shows an example of an accessory function $\mu_{\max }(x)$, which assigns to each object a degree of ownership in the range from zero to one.

Figure 1. An example characterized by the membership function (Compiled by the authors)

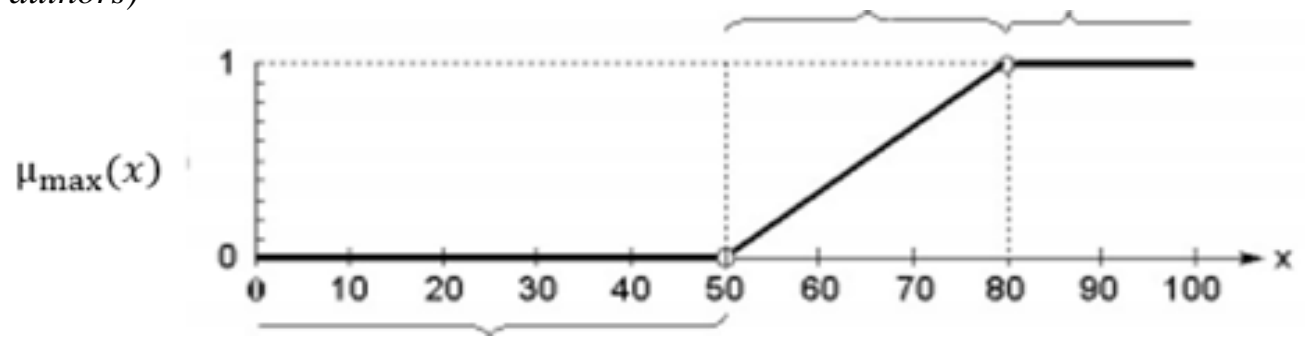

In this case, which is a set of high-risk customers, individuals with a risk level of $50 \%$ or less are assigned a minor membership score, and individuals with a risk level of $80 \%$ or more are assigned a different score. Between these risk levels $(50 \%$, $80 \%$ ) the classification assigned to the client's risk level is unclear. If the membership function has the shape shown in the figure, it is characterized as $\mathrm{S}$ shaped. Figure 2 shows examples of four other commonly used classes of membership function: triangular, trapezoidal, Gaussian, and bell-shaped. 
Figure 2. Examples of four other commonly used classes of membership function (Compiled by the authors)
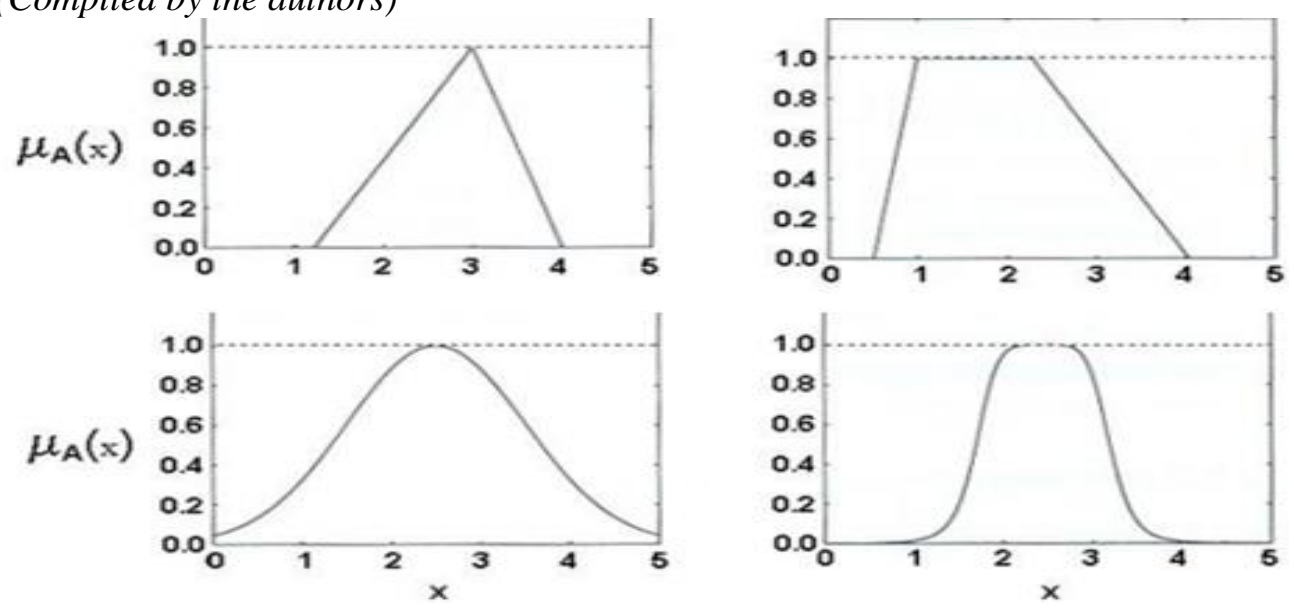

Fuzzy sets are realized by extending many basic identities that hold for ordinary sets. Thus, for example, the Union of two fuzzy sets, A and B, is often defined as the smallest fuzzy set containing both, that is:

$$
\mu_{A^{\mathrm{B}} \mathrm{B}}=\max \left[\mu_{A}(x), \mu_{\mathrm{B}}(x)\right], x \in \mathrm{X}
$$

and their intersection is usually defined as the largest fuzzy set that is contained in both, that is:

$$
\mu_{A^{A} \mathrm{~B}}=\min \left[\mu_{A}(x), \mu_{\mathrm{B}}(x)\right], x \in \mathrm{X}
$$

It is worth paying attention to the fact that the process of fuzzy modeling consists of two key stages: structure identification (the process of determining structural characteristics or the number of fuzzy rules and linguistic terms); identification of parameters (selection of previous and subsequent parameters). It is at this stage that the system error is minimized, so special attention should be paid to the optimization of this stage in the modeling of economic problems. An investment project is a specific plan or program of measures aimed at capital investments with their subsequent compensation and profit.

The net present value (NPV) - the total cash flow of the investment project without considering the payments associated with its financing, expressed by the formula, is taken as the main indicator of the effectiveness of the project:

$$
N P V=-I+\sum_{i=1}^{n} \frac{\Delta V_{i}}{\left(1+r_{i}\right)^{i}}+\frac{c}{\left(1+r_{N+1}\right)^{N+1}}
$$

$\mathrm{i}$ - period sequence number; 
$\Delta \mathrm{V}$ - difference between project financial flows in the $\mathrm{i}$-th period;

$\mathrm{r}$ - discount rate in the $\mathrm{i}$-th period;

$\mathrm{C}$ - liquidation value of assets after completion of the investment project.

It is usually assumed that a project is successful if the net present value of the project is greater than zero, that is $N P V>0$.

The next indicator that is used to perform the tasks of the work is the membership function $\mu_{r}: r \rightarrow[0: 1]$, NPV - some set of net present values. Fuzzy subset $r$ in NPV this is a graph display $\mu_{r}$. Herewith $\mu_{r}(N P V)$ is the degree of belonging NPV to $r$.

The fuzzy-multiple approach to assessing the risks of investment projects in the modern literature is increasingly common. The obvious difference of this method is that the parameters are described in the language of fuzzy sets, in contrast to standard statistical methods, where each risk factor acquires its probabilistic characteristics. Thus, the meaning of this method is to represent the profitability of the project in the form of a fuzzy number and the definition and maximization of its membership function while minimizing the risks of this project. It turns out that we need to estimate the values that make up the objective function in order to present it in a fuzzy form, and then determine the type of membership function in combination. In this case, the net present value function is the function that determines profitability.

The paper focuses on the construction of the most common triangular membership function, which is used when there is a lack of data for a more complex function. To build a function, you must specify a triangular number using 3 parameters: minimum value - $N P V_{\min }$, modal value - $N P V_{a v}$, and maximum value - $N P V_{\max }$, that is a triangular number $\mathrm{NPV}=\left(N P V_{\max } N P V_{a v} N P V_{\min }\right)$, that corresponds to optimistic, average and pessimistic outcomes. Thus, we get the following picture:

Figure 3. Triangular number with 3 parameters (Compiled by the authors)

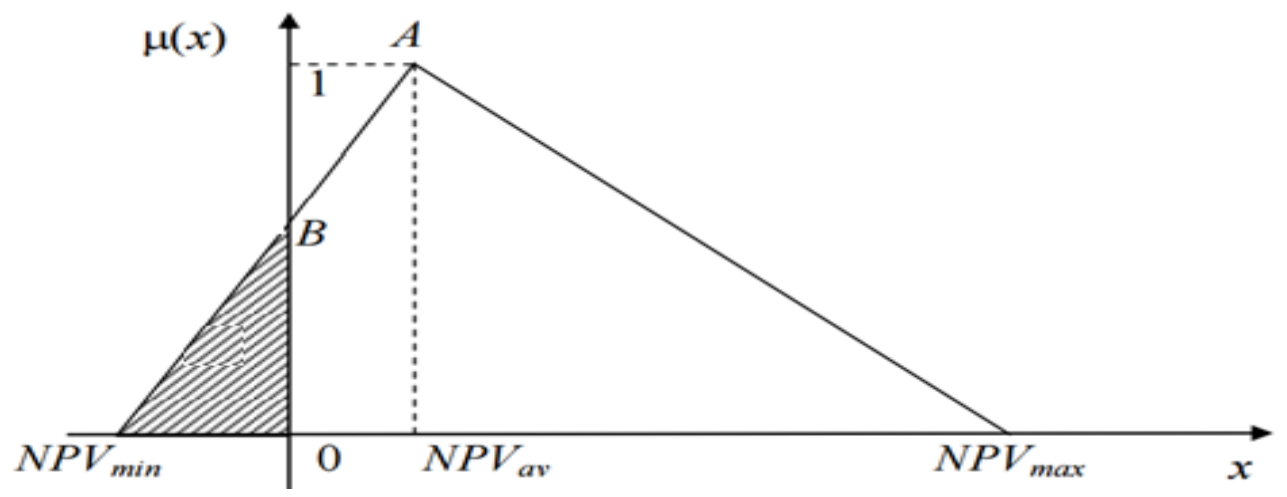


It was decided to take more points for the construction of the membership function in an expert way to compare the triangular method with a more accurate assessment and to understand whether it is possible to use the triangular method in this case or the use of this method will cause underestimation or reassessment of the risks of the investment project. To solve this problem, we use the method of risk assessment based on the integrated risk assessment V\&M (Voronov and Maximov). In addition to the previously introduced variables, we will use the $g$ - criterion of the project efficiency, which is usually assumed to be zero. The project is considered profitable if the NPV is greater than the criterion set by investors.

Defining the extreme values of NPV, we can describe a membership function:

$$
\begin{aligned}
& N P V_{1}=\propto\left(N P V-N P V_{\min }\right)+N P V_{\min } \\
& N P V_{2}=N P V_{\max }-\propto\left(N P V_{\max }-N P V_{a v}\right. \\
& V \& M^{*}=\int_{0}^{a_{1}} \varphi^{*}(\propto) d \propto,\left(^{*}\right) \\
& \text { где: } \varphi^{*}(\propto)=\left\{\begin{array}{r}
0, G \leq N P V_{1} \\
\frac{G-N P V_{1}}{N P V_{2}-N P V_{1}}, N P V_{1}<G<N P V_{2} \\
1, \quad N P V_{1} \leq G
\end{array}\right.
\end{aligned}
$$

Taking the integral, you can convert the above equations to form:

$$
V \& M^{*}=\left\{\begin{array}{c}
0, \quad G \leq N P V_{\min } \\
R \times\left(1+\frac{1-\propto_{1}}{\propto_{1}} \ln \left(1-\propto_{1}\right)\right), N P V_{\min } \leq G<N P V_{a v} \\
1-(1-R) \times\left(1+\frac{1-\propto_{1}}{\propto_{1}} \ln \left(1-\propto_{1}\right)\right), N P V_{a v} \leq G<N P V_{\max } \\
1, N P V_{\max } \leq G
\end{array}\right.
$$

where $R=\left\{\begin{array}{c}\frac{G-N P V_{\min }}{N P V_{\max }-N P V_{\min }}, G<N P V_{\max } \\ 1, N P V_{\max } \leq G\end{array}\right.$

$$
\propto_{1}=\left\{\begin{array}{c}
0, G \leq N P V_{\min } \\
\frac{G-N P V_{\min }}{N P V_{a v}-N P V_{\min }}, N P V_{\min } \leq G<N P V_{a v} \\
\frac{N P V_{\max }-G}{N P V_{\max }-N P V_{a v}}, N P V_{a v} \leq G<N P V_{\max } \\
0, N P V_{\max } \leq G
\end{array}\right.
$$


Assessment $V \& M^{*}$ : It takes values from 0 to 1 . Each investor, based on their investment preferences, can classify the values of V\&M, highlighting the segment of unacceptable risk values.

Advantages of the method: On the basis of the theory of fuzzy sets formed a full range of possible scenarios of the investment process; the decision is made not on the basis of two evaluations of the effectiveness of the project, but on the whole set of assessments; the expected efficiency of the project is not a point indicator, but a field of interval values with its distribution of expectations, characterized by the membership function of the corresponding fuzzy number.

Consider an investment project with the following indicators: Project duration: $\mathrm{t}=3$ years; the size of the initial investment: $\mathrm{I}=3$ million rubles; discount rate can range from $10 \%$ to $20 \%$; net present value of the flow is planned in the range $\mathrm{CF}_{\min }=0$ to $\mathrm{CF}_{\max }=3$ million rubles; residual value $=0$.

We use the fuzzy logic method for risk analysis (use equation 1 above):

$$
\begin{aligned}
& N P V_{\min }=-3+\frac{0}{(1+0,2)}+\frac{0}{(1+0,2)^{2}}+\frac{0}{(1+0,2)^{3}}=-3 \\
& N P V_{\max }=-3+\frac{3}{(1+0,1)}+\frac{3}{(1+0,1)^{2}}+\frac{3}{(1+0,1)^{3}}=4,46
\end{aligned}
$$

The average value of the net present value of the stream: $C F_{a v}=1,5$, average discount rate $r_{a v}=15 \%$

then $N P V_{a v}=-3+\frac{1,5}{(1+0,15)}+\frac{1,5}{(1+0,15)^{2}}+\frac{1,5}{(1+0,15)^{3}}=0,424$

Thus, the triangular number for the project in question is NPV $=(-3 ; 0,424 ; 4,46)$. We construct a graph of the membership function for this triangular number, shown below in Figure 4:

Figure 4. Graph of the membership function for a given triangular number (Compiled by the authors)

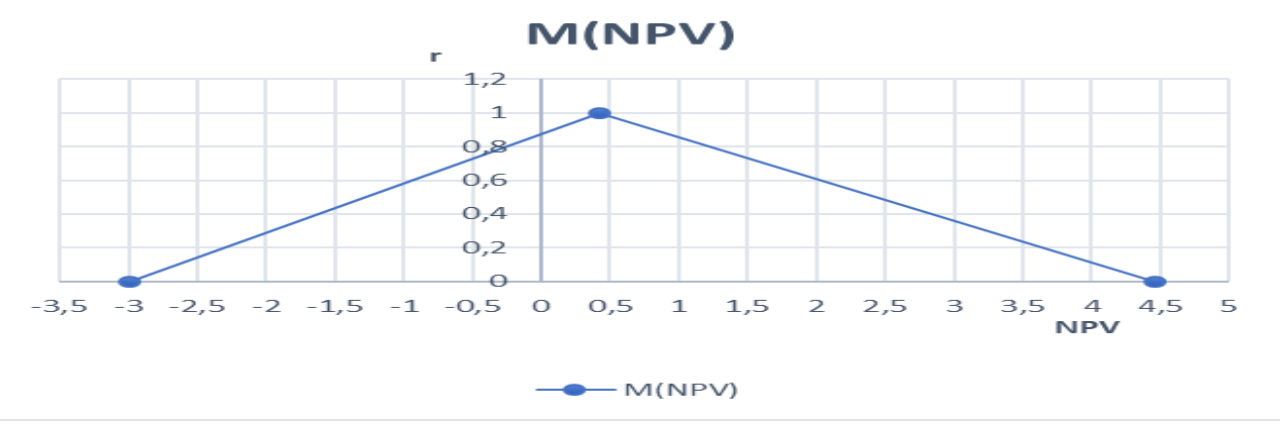


In this case, the zone of inefficient investments is the zone of NPV $\in[-3 ; 0]$. For a more accurate risk assessment, NPV were calculated for cases where $r=11 ; 12 ; 13$; $14 ; 16 ; 17 ; 18 ; 19 \%$, a $\mathrm{FC}=2,7 ; 2,4 ; 2,1 ; 1,8 ; 1,2 ; 0,9 ; 0,6 ; 0,3$ respectively. We also calculated the membership function for each point, for example, $\mu_{r}(N P V)$ if $\mathrm{r}=11 \%$ and $\mathrm{FC}=1,9$ as:

$\mathrm{NPV}=-3+\frac{2,7}{(1+0,11)}+\frac{2,7}{(1+0,11)^{2}}+\frac{2,7}{(1+0,11)^{3}}=3,598$

$\mu_{r}(N P V)=\frac{N P V_{\max }-3,598}{N P V_{\max }-N P V_{a v}}=\frac{4,46-3,598}{4,46-0,424}$

Thus, we obtain Table 1 for the data:

Table 1. Changes in numerical parameters (Compiled by the authors)

\begin{tabular}{|l|l|l|}
\hline$\mu_{r}(\mathrm{NPV})$ & $\mathrm{r}$ & $\mathrm{NPV}$ \\
\hline 0 & $10 \%$ & 4,46 \\
\hline 0,2136 & $11 \%$ & 3,598 \\
\hline 0,4202 & $12 \%$ & 2,764 \\
\hline 0,6199 & $13 \%$ & 1,958 \\
\hline 0,81296 & $14 \%$ & 1,1789 \\
\hline 1 & $15 \%$ & 0,424 \\
\hline 0,78709 & $16 \%$ & $-0,305$ \\
\hline 0,5808 & $17 \%$ & $-1,0114$ \\
\hline 0,3811 & $18 \%$ & $-1,695$ \\
\hline 0,1875 & $19 \%$ & $-2,358$ \\
\hline 0 & $20 \%$ & -3 \\
\hline
\end{tabular}

Comparing the graphs, we can conclude that in this problem we can rely on fewer data, because when comparing the graphs, we did not find that in the first case the risks were underestimated or overestimated. Since $N P V_{\min }<G=0<N P V_{a v}$, then using the formula V\&M (Voronov and Maximov):

$$
\begin{aligned}
& R=\frac{G-N P V_{\min }}{N P V_{\max }-N P V_{\min }}=\frac{0+3}{4,46+3}=0,402 \\
& a_{1}=\frac{G-N P V_{\min }}{N P V_{a v}-N P V_{\min }}=\frac{0+3}{0,424+3}=0,8762
\end{aligned}
$$




$$
\begin{aligned}
V \& M^{*}=R *(1 & \left.+\frac{1-a_{1}}{a_{1}} * \ln \left(1-a_{1}\right)\right)=0,402 *(1+0,141 *(-2,089)) \\
= & 0,283
\end{aligned}
$$

Based on data from Table 1, we derive Figure 5 as follows:

Figure 5. Schedule for more accurate risk assessment (Compiled by the authors)

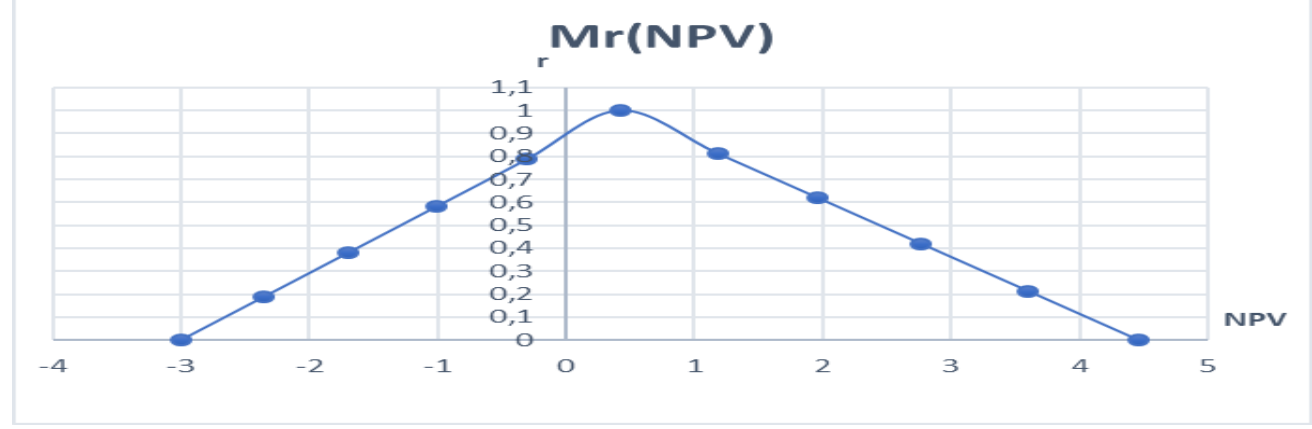

Risk manager independently sets the scale of risk aversion, depending on the additional parameters and their preferences. Using the following gradation shown in Table 2 we can estimate the risk level as follows:

Table 2. Risk aversion scale (Compiled by the authors)

\begin{tabular}{||l|l|l|}
\hline$V \& M$ & Degree of risk & The company's decision regarding the investment \\
\hline $\mathbf{0}-\mathbf{0 , 0 7}$ & Very low & Accurately accept the project \\
\hline $\mathbf{0 , 0 7}-\mathbf{0 , 1 5}$ & Low & $\begin{array}{l}\text { To accept, but with caution and subsequent } \\
\text { monitoring }\end{array}$ \\
\hline $\mathbf{0 , 1 6 - \mathbf { 0 , 3 5 }}$ & Average & Accept with restrictions \\
\hline $\mathbf{0 , 3 6 - \mathbf { 0 , 4 }}$ & High & Reject and revise the draft \\
\hline$>\mathbf{0 , 4 0}$ & Very high & To give with confidence \\
\hline
\end{tabular}

$0,16<\mathbf{0 , 2 8 3}<0,35$ this means that the degree of risk is average, and you can take this project with restrictions.

\section{Discussion}

The importance of considering a person's epistemological expectations in relation to cognitive decision-making and the individual's perception of future behavior is important for accurate risk assessment. Differences in the views of individuals on risk classification raise concerns that significant factors related to project functionality may be excluded from decision-making due to management's imbalance of attention to the planning, operation and control of strategic assets. Table 3 below shows the joint categorization of the differences between uncertainty and risk, which are characterized by assumptions made by decision makers (project managers) about the predictability of future events. 
Table 3. Risk and uncertainty category (Compiled by the authors)

\begin{tabular}{|l|l|}
\hline $\begin{array}{l}\text { Risk/uncertainty } \\
\text { category }\end{array}$ & Decision making \\
\hline $\begin{array}{l}\text { Risk category 1: } \\
\text { a-priori } \\
\text { probability }\end{array}$ & $\begin{array}{l}\text { The decision maker believes that it can calculate the mathematical } \\
\text { probability of potential events based on the reasonable application of } \\
\text { mathematical laws and algorithms. For example, the probability that } \\
\text { the roll of the cube will fall clearly one of six. }\end{array}$ \\
\hline $\begin{array}{l}\text { Risk category 2: } \\
\text { statistical } \\
\text { probability }\end{array}$ & $\begin{array}{l}\text { The decision maker believes that it can relate objective probabilities to } \\
\text { the probability of future events based on data collected from the } \\
\text { statistical probability of similar events in the past. For example, the } \\
\text { defeat of lightning. }\end{array}$ \\
\hline $\begin{array}{l}\text { Uncertainty } \\
\text { category 1: } \\
\text { subjective } \\
\text { probability }\end{array}$ & $\begin{array}{l}\text { Decision makers face a wide range of possible future events, but do } \\
\text { not have the information necessary to determine the objective } \\
\text { probability of the event, so they assign estimates based on the } \\
\text { historical expectations of the industry in the subjective probability of } \\
\text { future events. }\end{array}$ \\
\hline $\begin{array}{l}\text { Category of } \\
\text { uncertainty 2: } \\
\text { socialized } \\
\text { probability }\end{array}$ & $\begin{array}{l}\text { Decision makers face a wide range of scenarios where the number or } \\
\text { nature of future events is unknown. This is not due to difficulties in } \\
\text { understanding the specifics of the data, but rather to the amount of } \\
\text { relevant information available to the decision maker. It should be clear } \\
\text { to the decision-maker that the future is unknowable, as evidenced by } \\
\text { the nature of the "social construction" of the future. }\end{array}$ \\
\hline
\end{tabular}

Uncertainty may arise due to gaps in various areas of knowledge, such as contextual information about the project, or the degree of understanding of key processes, or the underestimation of specific past events. When the world is complex, flexible adaptation to the circumstances and the latest knowledge allow to obtain successful actions in overcoming uncertainty. Some other work focuses on the principle of foresight, based on the ability to anticipate the generation of knowledge in the early stages of project planning, and thus reduce uncertainty on contextual factors as quickly as possible.

\section{Conclusions}

Business economics is a multifactorial system, to predict behavioral characteristics, which is quite problematic, and at the same time it is focused on the end user. In addition, the economy is quite sensitive to the social trends of the industry. In most cases, it is possible to predict changes in economic activity under the influence of external and internal factors only in terms of linguistic (or fuzzy) concepts. Based on this, the priority in the economy is the use of fuzzy logic and fuzzy modeling.

In the practical part, we reviewed the investment project with specific data, found a triangular number of net present value and built a graph of its ownership function, also built a more detailed schedule and found that in this case there is no need to use a more detailed schedule. Using the risk assessment method of V\&M investment 
projects, it was found that this project has an average degree of risk and it is possible to accept this project with restrictions.

It can be concluded that at a time when processes are difficult to formalize and subjective criteria exist, fuzzy logic is more effective in using certain indicators in calculations and can be used to replace traditional algorithms or in conjunction with them. Also, fuzzy-multiple approach allows to reduce the amount of calculations, in comparison, for example, with probabilistic methods. Thus, in our case, fuzzy calculations allow us to assess all possible situations and calculate the possibility of risk occurrence, as well as to refer this project to a certain risk group and draw appropriate conclusions.

\section{References:}

Akerman, M. 2003. What does 'natural capital' do? The role of metaphor in economic understanding of the environment. Environmental Values, 12(4), 431-448.

Becker, G. 1976. The Economic Approach to Human Behavior, Chicago Press, 320.

Bell, D.E., Raïffa, H., Tversky, A. 1988. Decision making: Descriptive, normative, and prescriptive interactions. Cambridge, Cambridge University Press, 623.

Boardman, A.D., Greenberg, D., Vining, A., Weimer, D. 2001. Cost-Benefit Analysis: Concepts and Practice. Upper Saddle River, N.J., Prentice Hall.

Camerer, C. 2003. Behavioral game theory: experiments in strategic interaction. New York, Princeton, New Jersey, Russell Sage Foundation Princeton University Press.

Knight, F. 1921. Risk, Uncertainty and Profit. New York.

Saaty, T. 1993. Decision Making for Leaders: The Analytic Hierarchy Process. Moscow, Radio and Communication.

Saaty, T.L. 2008. Decision Making with Dependence and Feedback: The Analytic Network Process. Moscow, LCI Publisher.

Silvius, A., Schipper, R. 2014. Sustainability in project management: A literature review and impact analysis. Social Business, 4(1), 63-96.

Tversky, A., Kahneman, D. 1991. Loss aversion in riskless choice: A reference-dependent model. Quarterly Journal of Economics, 4(106), 1039-1061. 